\title{
Modelos de producción en el sector maquilador: tecnología, organización del trabajo y relaciones laborales*
}

\author{
Enrique de la Garza Toledo **
}

\begin{abstract}
T a idea central del programa de maquilas de exportación para el gobierno mexiLcano ha sido la de atraer capital con la finalidad de incrementar la inversión productiva, de crear empleo, lograr transferencia de tecnología, elevar la calificación de la mano de obra y equilibrar las balanzas de capitales y mercancías por la inversión extranjera directa y las exportaciones de la maquila. En esta medida, el gobierno mexicano estableció el régimen jurídico de maquila, que implica que la empresa maquiladora se inscriba formalmente como tal en la Secretaría de Economía, y que pueda importar temporalmente los bienes, maquinaria y equipo necesarios para el ensamble, la transformación o reparación de productos de exportación sin cubrir el pago de impuestos de importación, el valor agregado y las cuotas compensatorias; asimismo, el gozar de exención de impuestos de exportación por parte del gobierno mexicano y en parte del norteamericano (Amsden, 1997). Esta idea general ha tenido muchas modificaciones desde su establecimiento en 1964 y como régimen ha sido relativizado en los noventa con la entrada en operación del Tratado de Libre Comercio.
\end{abstract}

$\mathrm{Al}$ inicio del régimen de maquila su operación quedó restringida a la frontera norte, donde había localidades de escaso desarrollo industrial; las maquilas estaban obligadas a exportar su producción, de esta manera no competían con la industria nacional protegida en el modelo de sustitución de importaciones. Sólo podrían vender dentro de México si sus productos no se elaboraban aquí o bien si los insumos nacionales fueran de al menos el 20\% de los totales. En 1983 los proveedores

\footnotetext{
* Versión escrita de la conferencia especial presentada el 27 de octubre de 2004 en el IX Foro de Investigación: Congreso Internacional de Contaduría, Administración e Informática, organizado por la División de Investigación de la Facultad de Contaduría y Administración de la UNAM, México, D.F.

** Profesor-Investigador de la Universidad Autónoma Metropolitana, Iztapalapa.

Correro electrónico: egt@xanum.uam.mx
} 
nacionales de la maquila fueron autorizados a importar insumos. En 1989, con el inicio de la apertura de la economía, se buscó que las maquilas utilizaran insumos producidos en México y se estableció la necesidad de un permiso para vender en el mercado interno. En 1994 el porcentaje que podía venderse en el mercado interno pasó del 20\% al 55\% del valor de las exportaciones en el año, esto sin bajar el nivel de las exportaciones y manteniendo un superávit de divisas con el exterior. La firma del TLC abrió las posibilidades de desaparecer aranceles y restricciones a productos específicos para venderse en el mercado interno y a partir del 2001 toda la producción de la maquila puede venderse en México. En término de impuestos, las maquilas sólo pagan el ISR y sus exportaciones están exentas del pago del IVA, su producción para el mercado interno sí lo paga. En el 2001 se les obligó a pagar el $1.8 \%$ del Impuesto al Activo que fue diferido para no desalentar la inversión. En general, los productos de la maquila que entran a Estados Unidos están exentos de impuestos. La entrada en operación del TLC no eliminó el régimen de maquila, pero lo hizo menos atractivo, una empresa puede acogerse a las desgravaciones del TLC, o bien de la maquila o mezclarlos (Carrillo y Hualde, 2002).

Aunque las definiciones legales no sean las que puedan resolver el problema de si la maquila, además de ser un régimen jurídico con determinadas ventajas fiscales para que las empresas se inscriban, es un modelo de producción y de industrialización, conviene recordar como el Decreto para el Fomento y Operación de la Industria Maquiladora de Exportación del primero de junio de 1998 y su reforma del 13 de noviembre de 1998 define a la maquila como: proceso industrial o de servicio que implica transformación, elaboración o reparación de mercancías de procedencia extranjera importadas permanente o temporalmente para su exportación posterior. Lo anterior significa que la razón principal para que una maquila se registre como tal es porque no pagará los impuestos de importación de sus insumos, de la maquinaria y el equipo, así como el Impuesto al Valor Agregado, o bien porque los impuestos de importación se le restituirán posteriormente. Por lo que respecta a los impuestos de importación de los productos maquilados en México por parte de Estados Unidos, éstos se rigen principalmente por la partida No. 97.30 por la cual sólo se grava el valor agregado en México. En 2008 terminará la transición hacia el área de libre comercio de América del Norte, a partir de esa fecha los bienes intercambiados entre México y Estados Unidos que cumplan con las reglas de origen quedarán totalmente desgravados, no así los que no las cumplan (Gambrill, 1998). Si bien el requisito de exportar se ha eliminado con el TLC, el mercado principal de las maquilas sigue siendo el exterior. Por esta circunstancia, aunque la 
Modelos de producción en el sector maquilador: tecnología,

organización del trabajo y relaciones laborales

maquila ha incrementado su componente nacional y sus ventas al mercado interno, como veremos, sigue siendo un sector que importa la mayoría de sus insumos y que vende la mayor parte de su producción en el extranjero (Dussel, 2002).

Durante la década de los noventa la maquila de exportación se convirtió en el núcleo central del modelo económico, debido a su crecimiento casi explosivo en términos de empleo y producción. La industria maquiladora de exportación ha ocupado un lugar central dentro del sector manufacturero, representando en esa década el $47.9 \%$ de las exportaciones de la manufactura. Sin embargo, desde noviembre de 2000 la maquila dejó de crecer y tres años después seguía deprimida. Las causas de esta crisis han sido atribuidas a tres factores principales:

1) La caída en la demanda de productos de las maquilas debido a la recesión en la economía de los Estados Unidos.

2) La competencia con otros países con salarios más bajos que México, tales como China y los países de América Central, provocan el cierre de maquilas en México y su traslado hacia alguno de aquellos países.

3) El crecimiento de los salarios de la maquila en México en los últimos años, lo que habría reducido el margen de ganancia de este sector.

Excepto por la primera hipótesis, las explicaciones aceptan implícitamente que la maquila es un sector basado en bajos salarios, y, por tanto, que cuando esta ventaja nacional disminuye, la maquila tiende a salir del país o a cerrar simplemente sus plantas. Sin embargo, la polémica acerca de cuáles otros factores serían importantes y si el bajo salario se ha vuelto secundario es ahora más compleja debido a la existencia de una discusión más amplia en parte teórica y en parte de caracterización empírica (De la Garza, 2003).

Desde el punto de vista del desarrollo económico del país, la pregunta es si la maquila es una vía aceptable de crecimiento de la economía y de empleos dignos. La posición optimista acepta que la maquila empezó como trabajo de ensamble tipo fordista, con trabajo no calificado, mayoría de mujeres, bajos salarios, actividades repetitivas, tediosas, enajenadas; tecnología basada en herramientas o en máquinas no automatizadas; con organización taylorista del trabajo, con muy escasos encadenamientos productivos y de servicios en el territorio nacional. Sin embargo, añaden los partidarios de esta posición, la maquila ha tendido a transformarse a 
partir de la década de los ochenta en una actividad que no se reduce al ensamble, sino que incorpora procesos propiamente de manufactura, con tecnología automatizada, con nuevas formas de organización del trabajo, con obreros más calificados o un incremento en el porcentaje de técnicos de producción (por estas dos últimas circunstancias, con una tendencia a la masculinización de la fuerza de trabajo), que ha implicado mayor aprendizaje tecnológico y la formación de clusters y otros encadenamientos productivos y de servicios (Carrillo, 1989; Carrillo y Hualde, 1997; Lara, 1998; Gereffi, Spencer y Bair, 2002).

Es decir, la propuesta optimista relativa a la maquila la presenta como una vía aceptable de desarrollo industrial a través de una transición (upgrading) del ensamble sencillo a la manufactura compleja. Los argumentos del upgrading como un proceso evolutivo van en varios sentidos:

1) La constatación empírica, a través de estudios de caso, de que ya están presentes en México aspectos parciales de la maquila moderna (Kenney, 1998; Skalair, 1992).

2) La analogía con el sureste asiático, donde países como Corea del Sur, Taiwán, Singapur y Hong Kong empezaron en condiciones semejantes a las de México y actualmente son exportadores de manufacturas de alto valor agregado (Gereffi, Spencer y Bair, 2002).

3) La idea de que en México hay otras ventajas diferentes del bajo salario, como la cercanía con el mercado de los Estados Unidos, la infraestructura, el costo de la energía, una mano de obra educada, así como paz laboral y social. Las anteriores condiciones harían que México siga siendo atractivo, aunque los salarios no sean tan bajos como en otros países. Por tanto, si el salario no fuera la principal ventaja competitiva las maquilas tenderán hacia procesos de mayor valor agregado, con mano de obra más calificada y mejores salarios (Shaiken, 1990; Klein, Schuch y Triest, 2002).

4) La discusión teórica acerca del fin del taylorismo fordismo, que en el caso de las maquilas significa que las plantas tayloristas fordistas tendrían las limitaciones para aumentar la productividad propias de este modelo de producción, y, por tanto, habría una tendencia a cambiar de modelo de producción hacia otro de tipo toyotista, Lean Production o de especialización flexible que sería la explicación más profunda de sí hay cambio generacional en las maquilas (Wilson, 1996). 
Modelos de producción en el sector maquilador: tecnología, organización del trabajo y relaciones laborales

5) La tesis que rehuye la discusión teórica y que afirma que las maquilas no son una rama, una industria o un modelo de producción, sino un sector solamente caracterizado por un régimen arancelario y, por tanto, en la maquila cabrían muchas posibilidades de niveles tecnológicos, de organización, tipos de fuerza de trabajo; es decir, no habría una lógica productiva o de industrialización propia de las maquilas, sino sólo se caracterizarían por estar inscritas en un régimen arancelario (Carrillo, 1993).

Evidentemente que los argumentos optimistas sólo en parte son complementarios, en otros aspectos son contradictorios: los que hablan del upgrading difícilmente pueden coincidir con la idea de que la maquila es un simple régimen arancelario, porque se trataría de una transición hacia un modelo de producción y de industrialización más avanzado, por lo tanto, la maquila sería un modelo en transformación. Asimismo, la idea de generaciones de antigua y nueva maquila apunta también a formas diversas de producción y de industrialización, no se diga los que analizan el upgrading como resultado de la crisis del taylorismo fordismo. De lo anterior, se concluye que la tesis según la cual la maquila es un simple régimen arancelario, es la más superficial de todas las anteriores. Más aún, sus autores no son lógicamente consistentes al mezclar la idea de que es simplemente un régimen arancelario con la de un proceso de industrialización que evoluciona hacia generaciones más complejas (Carrillo y Hualde, 2002). Es cierto que una parte de la atracción de las maquilas es la exención de aranceles y tarifas, pero es válido el preguntarse si dicho régimen de aranceles junto a otros factores, como el bajo salario, atrajo preferentemente maquilas con ciertas características productivas. También es lícito preguntar el papel que jugaron ciertas relaciones con el entorno nacional (Dussel, 2002).

El problema central de la polémica acerca de la maquila es la llamada hipótesis de la dualidad tecnológica en este sector, que debería ser simplemente de la dualidad productiva porque el aspecto tecnológico es solamente uno de los que están en cuestión en esta discusión: si en la maquila hay dos tipos o generaciones, la antigua y la moderna, y si hay un proceso evolutivo de una a la otra.

Relacionados con la hipótesis central hay otras preguntas importantes:

1) Qué tan extendidas están las nuevas tecnologías controladas por computadora en la maquila, así como las nuevas formas de organización del trabajo (especialmente las más sofisticadas como el justo a tiempo y el control estadístico del 
proceso), o bien cuál es la importancia de los procesos productivos manufactureros con respecto de los de ensamble (Alonso, Carrillo y Contreras, 2002; De la O y Quintero, 2001).

2) Si la tendencia hacia la igualdad en el porcentaje de hombres y mujeres entre los obreros de la maquila es un indicador de incremento del trabajo calificado entre los obreros, al igual que lo es el crecimiento relativo de los técnicos de producción con respecto de los obreros (Barjas [coord.], 1989; González et al., 1995).

3) Si las condiciones de trabajo tienden a mejorar el salario, las prestaciones, los bonos, la higiene y seguridad, la estabilidad en el trabajo (Gambrill, 1995).

4) En particular hay una polémica muy intensa y variada acerca de las causas de la rotación externa de los trabajadores (Carrillo y Santibáñez, 1993; Cortés y Ruvalcaba, 1993; Kenney, 1998; González et al., 1995; Aguilar, 1996).

5) Si el bajo salario sigue siendo decisivo en la localización de las maquilas en México, que es una de las preguntas clave, porque de ser cierta podría relativizar las tesis del upgrading (Rodríguez, 1993).

6) Si ha cambiado el perfil de la mano de obra en la maquila, de mujeres jóvenes, sin experiencia laboral, hijas de familia y migrantes a otra y cuáles son sus implicaciones productivas (Carrillo, 1993; Wilson, 2002).

7) Cuáles serían las condiciones de vida de los trabajadores de la maquila y si tienden a mejorar (Sánchez, 1990).

Muchas de las preguntas anteriores se pueden resumir en si la maquila es un modelo de producción e industrialización. Por el primero se entiende una configuración productiva entre cierto nivel de la tecnología, forma de organizar el trabajo, tipo de relaciones laborales y condiciones de trabajo, perfil de la mano de obra (tanto sociodemográfico, de calificación y niveles salariales) y cultura laboral; por el segundo, formas de encadenamientos productivos y de servicios hacia delante y hacia atrás, vínculo con los mercados de la tecnología, de trabajo y de dinero, con el sistema de relaciones de trabajo de una zona o país, con las políticas económicas, con el mercado interno y externo, con el resto de la industria, la agricultura o los servicios (Boyer y Freyssenet, 2001). 
Modelos de producción en el sector maquilador: tecnología,

organización del trabajo y relaciones laborales

De manera complementaria, si en México hubiera obstáculos para extender el upgrading en la maquila, cuáles serían las causas y diferencias con el proceso seguido en el sureste asiático desarrollado (Wilson, 1996; sin autor, 1996). Lo anterior se relaciona con el análisis incompleto hasta hoy de las causas actuales de la crisis de la maquila.

En los siguientes apartados se busca responder a algunas de las preguntas planteadas en los párrafos anteriores.

\section{La importancia de la maquila en el modelo económico mexicano}

El concepto de modelo económico tiene varias acepciones; es común que se centre en el nivel macroeconómico y se analice con variables propias de las balanzas de pagos, se consideran en especial relaciones entre los grandes sectores de la economía, con el mercado externo de mercancías y de capitales, la intervención del estado en la inversión productiva o la regulación de los circuitos monetarios, en particular de las tasas de cambio, la inflación y las tasas de interés. Se acostumbra denominar modelo neoliberal a aquella economía y política económica en la que ha disminuido sustancialmente la inversión productiva del Estado (privatizaciones de por medio) y las políticas de fomento al crecimiento económico en las que se ha privilegiado el combate a la inflación con la regulación de la masa monetaria y la reducción de los déficits públicos sobre el crecimiento económico a las políticas de reducción de las barreras a la entrada y salida de mercancías y capitales del país; a las que han flexibilizado las regulaciones sobre las empresas y los mercados laborales. Sin embargo, un modelo económico no puede reducirse a la macroeconomía ni a la política económica, tiene que considerar las relaciones entre los tres grandes sectores de la economía, de éstos con el mercado externo, el papel del capital extranjero y, en otro nivel, los modelos productivos dominantes. En esta medida, en México, además de ajustes genéricos propios del modelo neoliberal se acuñó al mismo tiempo como parte del modelo económico un aparato productivo secundario exportador (que no es una característica genérica de todos los modelos neoliberales) y en particular maquilador que desplazó al petróleo como fuente de divisas y se convirtió en el motor de la economía. En este sector juega un papel central la inversión extranjera directa, que durante su período de oro se dirigió más a la inversión productiva que a la especulación financiera (De la Garza, 2001).

Como se ve en el cuadro No. 1, el PIB de la manufactura con respecto del PIB nacional creció entre 1990 y el 2000 de $19.6 \%$ al $21.5 \%$ para luego decaer con la 
crisis de los primeros años de este siglo. Más importante ha sido el impacto del sector manufacturero en la exportación total, que pasó de representar en 1990 el $68.4 \%$ del total de las exportaciones al 89.2\% en el 2001 para luego decaer con la crisis actual. De esta exportación manufacturera la maquila ha llegado a representar más de la mitad (54.5\% en el 2002) y con respecto de las exportaciones totales la maquila significa casi el 50\%. En cuanto a su impacto en la ocupación formal, la maquila en su punto máximo representó en el 2000, 1,291,232 trabajadores directos para luego disminuir. En el empleo manufacturero la maquila en el 2002 alcanzó el $40 \%$.

\section{Cuadro 1}

\section{Importancia de la maquila en la exportación, en el empleo y su contribución al PIB}

\begin{tabular}{|c|c|c|c|c|c|c|c|}
\hline & 1990 & 1998 & 1999 & 2000 & 2001 & 2002 & 2003 \\
\hline PIB manufactura/PIB & 19.6 & 21.3 & 21.4 & 21.5 & 20.8 & 20.5 & 19.9 \\
\hline $\begin{array}{l}\text { Exportación } \\
\text { manufactura/exportación } \\
\text { total }\end{array}$ & 68.4 & 90.3 & 89.5 & 87.3 & 89.2 & 88.3 & 84.7 \\
\hline $\begin{array}{l}\text { Valor Agregado en } \\
\text { maquila/PIB } \\
\text { manufactura }\end{array}$ & 7.0 & 13.1 & 15.0 & 16.1 & 17.4 & 17.1 & 7.3 \\
\hline $\begin{array}{l}\text { Exportación } \\
\text { maquila/exportación } \\
\text { total }\end{array}$ & 34.1 & 45.2 & 46.8 & 47.7 & 48.5 & 48.6 & 47 \\
\hline $\begin{array}{l}\text { Exportación } \\
\text { maquila/exportación } \\
\text { manufactura }\end{array}$ & $\begin{array}{r}49 \% \\
(1991)\end{array}$ & 49.8 & 52 & 54.2 & 54.1 & 54.5 & nd \\
\hline $\begin{array}{l}\text { Personal } \\
\text { maquila/personal } \\
\text { manufactura }\end{array}$ & 13.6 & 26.9 & 29.2 & 31.5 & 30.8 & 40.0 & nd \\
\hline $\begin{array}{l}\text { Personal total ocupado } \\
\text { en la maquila }\end{array}$ & 46,436 & $1,014,006$ & $1,143,240$ & $1,291,232$ & $1,198,942$ & $1,071,209$ & $1,062,105$ \\
\hline
\end{tabular}

Fuente: Vicente Fox (2004), Cuarto informe de gobierno

Sin embargo, tanto la maquila como el sector manufacturero entraron en crisis a partir del año 2000. El personal ocupado entre el 2000 y el 2003 se redujo en $17.7 \%$, el número de establecimientos maquiladores en $20.5 \%$, la tasa de crecimiento del volumen físico de la producción maquiladora reconoció tasas negativas a partir del 2001, la tasa de crecimiento de la productividad también fue negativa en el $2001(-2.8 \%)$, muy baja en el 2002 (1.7\%) y nuevamente negativa en el 2003 $(-1.0 \%)$. Aunque, como veremos, las dificultades productivas de este sector se iniciaron con anterioridad a la crisis de principios de este siglo. Las exportaciones de la maquila entre el 2000 y el 2003 se han reducido en $2.5 \%$ y la inversión extranjera directa en $34.3 \%$. A pesar de que en el 2004 los indicadores menciona- 
Modelos de producción en el sector maquilador: tecnología,

organización del trabajo y relaciones laborales

dos han mejorado, no hay todavía certeza de que la maquila logrará recuperar el papel que tuvo en los años noventa en el modelo económico mexicano. En esta medida muchas voces se han manifestado preguntándose si el modelo maquilador llegó a su límite y si es posible emprender un camino diferente de crecimiento económico.

\section{Cuadro 2}

Indicadores de crisis de la maquila

\begin{tabular}{|l|r|r|r|r|} 
& \multicolumn{1}{|c|}{2000} & \multicolumn{1}{|c|}{2001} & \multicolumn{1}{|c|}{2002} & \multicolumn{1}{|c|}{2003} \\
\hline Personal total ocupado & $1,291,232$ & $1,198,942$ & $1,071,209$ & $1,062,105$ \\
No. Establecimientos & 3,598 & 3,630 & 3,003 & 2,860 \\
\hline $\begin{array}{l}\text { Crecimiento tasa volumen físico de la } \\
\text { producción }\end{array}$ & 13.8 & -9.7 & -9.1 & -1.0 \\
\hline Tasa de crecimiento de productividad & 0.9 & -2.8 & 1.7 & -0.1 \\
Exportaciones (millones de Dls.) & 79,467 & 76,881 & 78,098 & 77,476 \\
\hline $\begin{array}{l}\text { Inversión extranjera en maquiladoras } \\
\text { (millones dls.) }\end{array}$ & 2,983 & $2,172.2$ & $2,043.5$ & $1,961.1$ \\
\hline
\end{tabular}

Fuente: Vicente Fox (2004), Cuarto informe de gobierno

Un problema relacionado con la crisis de la maquila es si se debe sólo a factores externos a la economía mexicana como la competencia de países de más bajos salarios que México, la recesión en los Estados Unidos que impactó directamente a la demanda de productos maquiladores, o bien hay factores internos primero nacionales (la política salarial del gobierno que se ha traducido en incrementos reales de los salarios en la maquila aun en estos años de crisis, la falta de infraestructura suficiente de transporte, los precios de la energía, los trámites burocráticos) y otros relacionados con la manera de producir de la maquila. Utilizaremos el concepto de modelos de producción para referirnos a la configuración entre tecnología, organización del trabajo, relaciones laborales, perfil de la mano de obra, culturas laborales y gerenciales y el de modelo industrial que comprendería además de los modelos productivos sus articulaciones en el país con clientes y proveedores, con el mercado de trabajo, con el de la tecnología, con el del dinero, con el sistema político.

Tanto los modelos productivos como los industriales en ciertas condiciones del mercado, institucionales y políticas, pueden llegar a sus límites para incrementar la productividad y la competitividad. La pregunta es, por tanto, si es posible caracterizar modelos productivos centrales en la maquila, a diferencia de la tesis que dice que es un simple régimen arancelario, y si las dificultades actuales de la maquila en parte se explican por límites en las formas como se produce. El análisis de estos 
problemas tiene que ir al interior de los procesos productivos y sus articulaciones con el entorno; éstos tienen manifestaciones en variables económicas que por su carácter general hay que profundizar de la primera forma puesto que su medición puede tener diversos significados.

El análisis de las tasas de crecimiento de la productividad del trabajo en la maquila a partir de 1990 muestra que éstas fueron muy bajas o francamente negativas con excepción de los años de 1990 y 1994; es decir, el gran crecimiento de los noventa en la inversión, producción, exportación y empleo en la maquila no se compaginó con tasas semejantes de crecimiento de la productividad. Por el contrario, éstas no sólo fueron mediocres, sino en muchos años negativas, en especial a partir de 2000 se inició otra etapa de crecimiento en general negativa en este indicador. A contracorriente, el índice de remuneraciones reales en la maquila que, después de una caída en 1995 y 1996 relacionada con la crisis de esos años, se ha recuperado sostenidamente, incluyendo los tres primeros años de este siglo, aunque en el 2003 experimentó un ligero retroceso.

\section{Cuadro 3}

Tasa de crecimiento anual de la productividad del trabajo e índices de las remuneraciones reales al personal total ocupado en la manufactura y en la maquila, 1993=100

\begin{tabular}{|l|rr|r|}
\hline & $\begin{array}{l}\text { Tasa de incremento } \\
\text { productividad en maquila }\end{array}$ & $\begin{array}{l}\text { Índice de remuneraciones } \\
\text { reales en maquila }\end{array}$ \\
\hline 1990 & 14.5 & 100.4 \\
\hline 1991 & -1.8 & 98.5 \\
\hline 1992 & 1.8 & 100.2 \\
1993 & 0.0 & 100 \\
\hline 1994 & 3.7 & 104.5 \\
\hline 1995 & 0.4 & 99.9 \\
\hline 1996 & -0.4 & 93.0 \\
\hline 1997 & -0.5 & 94.5 \\
\hline 1998 & -0.7 & 98.3 \\
\hline 1999 & -0.4 & 100.4 \\
\hline 2000 & 0.9 & 104.7 \\
\hline 2001 & -2.8 & 113.2 \\
\hline 2002 & 1.7 & 118.3 \\
\hline 2003 & -0.1 & 117.0 \\
\hline
\end{tabular}

Fuente: Vicente Fox (2004), Cuarto informe de gobierno 
Modelos de producción en el sector maquilador: tecnología, organización del trabajo y relaciones laborales

Otros indicadores económicos para la maquila muestran que hasta 2001, año de crisis, la dependencia del valor agregado con respecto de los salarios era tan elevado como del 80\%; sin embargo en 2002 y 2003 ha disminuido sustancialmente; las ganancias con respecto de las remuneraciones decayeron sostenidamente durante casi toda la década de los noventa y en general continuaron con esa tendencia hasta los años actuales de crisis. La ganancia con respecto del valor agregado, después de cierto repunte a mediados de los noventa, se estancó y ha decrecido en los últimos años. Finalmente, la tasa de ganancia en la maquila ha tenido un comportamiento irregular, alta a inicios de los noventa, disminución con la crisis de medidos de esa década, recuperación de fines de siglo y nueva disminución con la crisis actual; es decir, los indicadores económicos como los mencionados no nos señalan un sector muy saludable desde inicios de la década de los noventa, que probablemente ya tenía dificultades productivas antes de la crisis actual, a pesar de que en la década pasada reconoció años de gran demanda por parte del mercado de los Estados Unidos.

\section{Cuadro 4}

Productividad y tasa de ganancia en la maquila en los noventa

\begin{tabular}{c|r|r|r|r|r}
\hline Año & \multicolumn{1}{|c|}{$\begin{array}{c}\text { Índice de } \\
\text { Productividad }\end{array}$} & Rem/VA & G/Rem & Tg & \multicolumn{1}{c}{ G/VA } \\
\hline 1990 & 96.0 & 0.76 & 0.32 & 4.2 & 0.24 \\
\hline 1991 & 94.2 & 0.73 & 0.37 & 4.6 & 0.27 \\
\hline 1992 & 96.1 & 0.81 & 0.23 & 3.3 & 0.19 \\
1993 & 96.1 & 0.81 & 0.24 & 3.2 & 0.19 \\
\hline 1994 & 99.6 & 0.82 & 0.22 & 1.7 & 0.18 \\
\hline 1995 & 100.0 & 0.78 & 0.29 & 2.3 & 0.22 \\
\hline 1996 & 99.6 & 0.79 & 0.27 & 2.3 & 0.21 \\
\hline 1997 & 93.9 & 0.80 & 0.25 & 2.5 & 0.20 \\
\hline 1998 & 93.4 & 0.78 & 0.28 & 2.7 & 0.22 \\
\hline 1999 & 92.9 & 0.78 & 0.29 & 3.0 & 0.22 \\
\hline 2000 & 93.9 & 0.82 & 0.22 & 2.5 & 0.18 \\
\hline 2001 & 91.2 & 0.80 & 0.25 & 3.0 & 0.20 \\
\hline 2002 & & 0.48 & 0.23 & 2.8 & 0.11 \\
\hline 2003 & & 0.46 & & &
\end{tabular}

Fuente: Elaboración propia a partir de la encuesta nacional de la Industria Maquiladora del INEGI

$\mathrm{Tg}=$ ganancia/(Insumos+Remuneraciones+Depreciación)

$\mathrm{G}=$ ganancias

Rem $=$ remuneraciones

$\mathrm{VA}=$ Valor agregado 


\section{2. ¿Qué es la maquila de exportación en México?}

La maquila es en principio un régimen arancelario con características como las mencionadas más arriba, pero muestra regularidades como aparato industrial como las siguientes:

1) Hay un predominio de establecimientos grandes (más de 250 trabajadores) en comparación con la importancia de los medianos (entre 100 y 249 trabajadores) y pequeños (entre 15 y 99 trabajadores) en cuanto a porcentaje de los establecimientos (43.1\% en 1999), aunque este porcentaje disminuyó con la crisis actual, y es especialmente abrumadora la importancia de los grandes establecimientos en cuanto al porcentaje de personal ocupado, el valor de la producción y el capital fijo invertido. Habría que aclarar que con la crisis actual esos porcentajes han disminuido, pero siguen siendo muy elevados, como se ve en el cuadro No. 5.

\section{Cuadro 5}

Importancia de los establecimientos grandes (más de 250 trabajados) en la maquila de exportación

\begin{tabular}{|lr|c|}
\hline $\begin{array}{l}\text { Porcentaje del total de } \\
\text { establecimientos }\end{array}$ & $\begin{array}{r}1999 \\
43.1\end{array}$ & 3601 \\
\hline $\begin{array}{l}\text { Porcentaje del personal } \\
\text { total ocupado }\end{array}$ & 87.3 & 78.8 \\
\hline $\begin{array}{l}\text { Porcentaje del capital fijo } \\
\text { invertido } \\
\text { Porcentaje del valor de la } \\
\text { producción }\end{array}$ & 96.3 & 76.1 \\
\hline
\end{tabular}

Fuente: INEGI $(199,2002)$ ENESTYC

2) La importancia del capital extranjero en la maquila es notable, en número de establecimientos se mantiene aún con la crisis en $58.1 \%$ en el 2001 , y en el porcentaje de capital fijo invertido su importancia es abrumadora $(76.3 \%$ en el 2001), además de que la gran mayoría de los establecimientos de capital extranjero son subsidiarías de corporaciones (98.4\% en 1999 y $63.7 \%$ en el 2001).

3) Hay un claro predominio del capital y las subsidiarias de los Estados Unidos sobre las de los otros países que participan en la maquila (87.4\% en 1999 y $91.0 \%$ en 2001). 
Modelos de producción en el sector maquilador: tecnología, organización del trabajo y relaciones laborales

4) La mayor parte de los insumos de la maquila son importados (87.4\% en 1999 y $84.1 \%$ en el 2001); no hubo un proceso de sustitución de insumos importados por nacionales durante la crisis.

5) La gran mayoría de los insumos importados provienen de Norteamérica $(82.15 \%$ en 1999 y $80.2 \%$ en 1991) no hubo un proceso de sustitución de insumos importados de USA por los de otras regiones con la crisis.

6) La mayoría de los ingresos obtenidos por la maquila son por exportación (73.5\% en 1999 y se incrementaron a $85.4 \%$ en el 2001), es decir, la crisis no implicó una reorientación hacia el mercado interno.

7) La inmensa mayoría de la exportación de la maquila se dirige hacia Norteamérica (90.4\% en 1989 y aumentó a 95.5\% en el 2001); la crisis no implicó la búsqueda de la maquila de mercados diferentes al de USA.

Es decir, la maquila de exportación en México es principalmente una gran empresa, de capital extranjero, norteamericano, filial de corporaciones, que importa la mayoría de sus insumos y exporta la mayor parte de su producción. La crisis sacó del mercado principalmente a las grandes empresas, que conocen mejor el mercado internacional y probablemente hayan sido las que se trasladaron a otros países; afectó a las de capital extranjero en mayor medida y en especial a las de Estados Unidos, filiales de corporaciones.

\section{Cuadro 6}

\section{Importancia del capital extranjero en la maquila}

\begin{tabular}{|lc|c|}
\hline Porcentaje del total de establecimientos & 1999 & 2001 \\
\hline Porcentaje del total de capital fijo invertido & 64.10 & 58.20 \\
\hline $\begin{array}{l}\text { Porcentaje de subsidiarias con respecto de lo } \\
\text { establecimiento de capital extranjero }\end{array}$ & 96.70 & 76.28 \\
$\begin{array}{l}\text { Establecimiento de los USA con respecto de los de capital } \\
\text { extranjero }\end{array}$ & 98.40 & 63.70 \\
\hline $\begin{array}{l}\text { Subsidiarias de USA con respecto de las subsidiarias } \\
\text { extranjeras }\end{array}$ & 87.40 & 90.40 \\
\hline $\begin{array}{l}\text { Porcentaje de capital USA con respecto de las de capital } \\
\text { extranjero }\end{array}$ & 96.70 & 91.00 \\
\hline $\begin{array}{l}\text { Porcentaje de exportaciones hacia Norteamérica } \\
\text { Porcentaje de insumos importados de Norteamérica }\end{array}$ & 90.40 & 95.50 \\
\hline $\begin{array}{l}\text { Porcentaje que representan las exportaciones en el total de } \\
\text { ingresos }\end{array}$ & 73.50 & 80.20 \\
\hline Porcentaje de insumos importados en el total de insumos & 87.40 & 87.10
\end{tabular}

Fuente: INEGI $(1999,2002)$ ENESTYC 


\section{Los modelos de producción en la maquila}

Las características de los modelos de producción en la maquila las analizaremos a partir de dos encuestas. La primera es la Encuesta Nacional de Empleo, Salarios, Tecnología y Capacitación (ENESTYC), que es una encuesta nacional levantada entre el INEGI y la Secretaría del Trabajo con una muestra representativa para el sector manufacturero de 5,000 establecimientos y que para los años de 1999 y 2001 cuenta con un módulo especial para la maquila de exportación. La otra es la Encuesta sobre Modelos de Industrialización en la Maquila (EMIM) aplicada en 100 establecimientos de la zona centro sureste del país en el 2003 por el posgrado en Estudios Laborales de la UAM-I.

Tecnológicamente hablando, el porcentaje del valor de la maquinaria y el equipo invertido de tipo manual y en máquinas herramientas no automáticas, que serían del nivel tecnológico más bajo, diferente del equipo automático y del automático computarizado como los robots, constituye el más elevado ( $83.22 \%$ en 1999 y $54 \%$ en el 2001). El cambio hacia la baja en este tipo de maquinaria y equipo de bajo nivel tecnológico al inicio de la crisis de la maquila podría significar que se han ido o cerrando sobre todo las plantas de tecnología más baja o las más intensivas en fuerza de trabajo atraídas por países en los que la ventaja estaría en este renglón. Sin embargo, el porcentaje del valor de estos instrumentos de producción de bajo nivel tecnológico en la maquila permanece por arriba del 50\%. Indicadores complementarios del nivel tecnológico son los de porcentaje de los ingresos destinados a la inversión en tecnología, de 2\% en 1999 no han cambiado mucho en 2001 con $1.82 \%$. Es decir, la aparente modernización de la maquinaria y el equipo del primer indicador no sería por nuevas inversiones, sino por el cierre de las plantas más anticuadas y la permanencia de las más modernas tecnológicamente. Lo anterior se compagina con el porcentaje de los ingresos dedicados a investigación y desarrollo continúan casi inexistentes con crisis o sin crisis. Finalmente, el porcentaje de establecimientos que se provee de tecnología por simple transferencia de la casa matriz o copiándola de literatura especializada o de eventos especializados es la mayoría y no ha cambiado con la crisis. 
Modelos de producción en el sector maquilador: tecnología,

organización del trabajo y relaciones laborales

\section{Cuadro 7}

\section{Indicadores de nivel tecnológico en la maquila}

\begin{tabular}{|l|c|c|}
\hline $\begin{array}{l}\text { Porcentaje del valor de equipo manual y } \\
\text { máquinas herramientas no automáticas en el total } \\
\text { del valor de maquinaria y equipo en operación }\end{array}$ & 83.22 & 54.00 \\
$\begin{array}{l}\text { Porcentaje de los ingresos destinados a inversión } \\
\text { en tecnología }\end{array}$ & 2.00 & 1.82 \\
\hline $\begin{array}{l}\text { Porcentaje de los ingresos dedicados a } \\
\text { investigación y desarrollo }\end{array}$ & 0.00 & 0.07 \\
\hline $\begin{array}{l}\text { Porcentaje de establecimiento que se proveen } \\
\text { principalmente de tecnología a partir de la casa } \\
\text { matriz y por medio de literatura, asesorías y en } \\
\text { eventos especiales }\end{array}$ & 66.60 & 67.80 \\
\hline
\end{tabular}

Fuente: INEGI $(1999,2002)$ ENESTYC

Cuadro 8

Características de la tecnología en la maquila

\begin{tabular}{|l|c|}
\hline \multicolumn{1}{|c|}{ Indicador de nivel tecnológico } & $\begin{array}{c}\text { Porcentaje de } \\
\text { establecimientos }\end{array}$ \\
\hline Autoevaluación de tener tecnología atrasada & 51.0 \\
\hline Predomina forma de Control de calidad visual & 76.9 \\
\hline No utiliza el sistema Justo a Tiempo & 61.5 \\
\hline Desarrolla su propia tecnología & 14.3 \\
No realiza investigación y desarrollo & 82.7 \\
\hline
\end{tabular}

Fuente: Elaboración propia a partir de la encuesta EMIM (2004)

A partir de la encuesta EMIM, para la zona centro sureste de México, se observa que las maquilas se autoevalúan muy alto en cuanto a tener tecnología atrasada (51\%); en este sector predomina ampliamente el control de calidad visual no por medio de instrumentos $(76.9 \%)$, seguido de control con instrumentos no automatizados (14.4\%) y al final el control de más alto nivel con instrumentos automatizados en sólo el $8.7 \%$ de los establecimientos encuestados. La mayoría no desarrollan su propia tecnología y no hacen investigación y desarrollo. El principal procedimiento para adquirir tecnología es la transferencia de la casa matriz $(37.8 \%$ de los casos) seguida de la compra a otras empresas (31.6\%) 
Los resultados anteriores son consecuentes con los datos nacionales de la maquila que en general no utiliza la alta tecnología y menos la desarrolla en sus instalaciones.

\section{Cuadro 9}

\section{Indicadores de cambio organizacional en la maquila}

Fuente: INEGI $(1999,2002)$ ENESTYC

Nota: los porcentajes no deben sumarse porque los cambios pueden

suceder en un mismo establecimiento

\section{Cuadro 10}

\section{Nuevas formas de organización del trabajo en la maquila}

\begin{tabular}{|ll|}
\hline & 2003 \\
\hline Tienen círculos de calidad & 26.9 \\
\hline Tienen equipos de trabajo & 40.4 \\
\hline Células de producción & 30.8 \\
\hline Control total de la calidad & 37.5 \\
\hline Reingeniería & 15.4 \\
\hline Cero errores & 20.2 \\
Control estadístico del proceso & 32.7 \\
\hline Kan ban & 12.5 \\
\hline
\end{tabular}

Fuente: EMIM (2003)

Nota: los porcentajes no deben sumarse porque un mismo establecimiento puede tener varias formas nuevas de organización.

En 1999 solamente el 14.1\% instalaron justo a tiempo y/o control estadístico del proceso, que son dos de las formas complejas y nuevas de organización del trabajo y en 2001 aumentaron al 24\%; en cambio, el control total de la calidad se estableció en 1999 en el $29.8 \%$ de los establecimientos y en el 2001 en el $24.4 \%$.

Lo anterior se compagina con la información de la extensión de círculos de calidad, equipos de trabajo, células de producción, control total de la calidad, reingeniería, cero errores, control estadístico del proceso o kan ban, que en la mayoría de las maquilas de la muestra para la zona centro sureste no se practican, siendo los más utilizados los equipos de trabajo seguidos del control total de la calidad. 
Modelos de producción en el sector maquilador: tecnología, organización del trabajo y relaciones laborales

\section{Cuadro 11}

\section{Características de la organización del trabajo en la maquila}

\begin{tabular}{|l|l}
\hline El control de calidad lo hace un departamento especializado & 72.5 \\
\hline $\begin{array}{l}\text { El examen de habilidades es el principal procedimiento para asignar a un nuevo } \\
\text { trabajador a un puesto }\end{array}$ & 55.3 \\
\hline $\begin{array}{l}\text { El examen de habilidades y dominio de tareas es el principal procedimiento para } \\
\text { el ascenso de un trabajador }\end{array}$ & 69.3 \\
\hline Los establecimientos cuentan con manuales de puestos y los utilizan & 54.9 \\
\hline $\begin{array}{l}\text { Los establecimientos cuentan con manuales de procedimientos y los utilizan } \\
\text { Se realizan estudios de tiempos y movimientos }\end{array}$ & 58.7 \\
\hline Los trabajadores cumplen cuotas mínimas de producción & 77.9 \\
\hline El personal especializado es el que realiza las tareas de mantenimiento & 81.6 \\
\hline La supervisión que predomina es por medio de jefes y supervisores & 65.4 \\
\hline La forma de comunicación de arriba hacia abajo que predomina es verbal directa & 56.3 \\
\hline La principal forma que predomina de abajo hacia arriba es verbal directa & 62.1 \\
\hline
\end{tabular}

Fuente: Elaboración propia a partir de la encuesta EMIM (2004)

Los indicadores de la encuesta EMIM no apuntan al predominio de las formas toyotistas de organización del trabajo sino de las tayloristas fordistas. El mantenimiento, el control de calidad y la supervisión del personal se realizan principalmente a partir de personal especializado en una división de tareas distante de la autosupervisión, del autocontrol de calidad o la realización de tareas combinadas de producción, mantenimiento y control de calidad. Sin embargo, hay que reconocer que el porcentaje de establecimientos que no realiza control de calidad es muy pequeño $(1 \%)$ y que alrededor de una cuarta parte es el personal de producción el que efectúa el control de calidad, aunque la proporción de los establecimientos en los que los trabajadores de producción realizan el mantenimiento es pequeño (13.4\%) y todavía más pequeño el número de aquellos en los que la supervisión del personal se realiza con equipo automatizado $(3.8 \%)$ o por los propios equipos de trabajo $(5.8 \%)$. Es decir, en este tipo de división del trabajo hay un predominio claro de las concepciones tayloristas de separación entre las tareas de producción con la de control de calidad, mantenimiento y supervisión.

La anterior aseveración se refuerza porque la mayoría de los establecimientos tienen y utilizan manuales de puestos y de procedimientos; hacen estudios de tiempos y movimientos y los trabajadores tienen que cumplir cuotas mínimas de producción. Además, son los exámenes de habilidades, no de conocimientos, los criterios principales para el ingreso o el ascenso de los trabajadores, con un papel muy marginal de los equipos de trabajo en la selección o promoción del personal. Final- 
mente, las formas de comunicación son tradicionales en cuanto a que predominan en las de arriba hacia abajo o de abajo hacia arriba las formas orales directas por medio de jefes o supervisores.

\section{Cuadro 12}

\section{Indicadores de flexibilidad interna del trabajo en la maquila}

\begin{tabular}{|l|c|}
\hline & $\begin{array}{c}\text { Porcentaje de } \\
\text { establecimientos }\end{array}$ \\
\hline Los trabajadores son movidos frecuentemente de puesto o categoría & 10.7 \\
\hline Los trabajadores muy frecuentemente son movidos de turnos & 48.1 \\
Muy frecuentemente los trabajadores realizan tareas de diferentes puestos & 52.3 \\
\hline El trabajo en horas extras es de nivel intermedio, no frecuentemente & 46.7 \\
\hline Muy frecuentemente los obreros trabajan en días de descanso obligatorios & 70.4 \\
\hline La rotación de turnos es regular (no frecuente) & 46.8 \\
Muy frecuentemente los trabajadores cambian de departamento & 65.7 \\
\hline Muy frecuentemente cambian de establecimiento de la misma empresa & 80.0 \\
\hline
\end{tabular}

Fuente: Elaboración propia a partir de la encuesta EMIM (2004)

En cuanto a la flexibilidad del trabajo no se acostumbra mover frecuentemente a los trabajadores entre puestos o categorías, aunque la ausencia de movilidad de este tipo también es muy baja (12.6\%); predominan más los niveles esporádico y regular, propios de una organización taylorista fordista donde se considera mejor que haya para cada puesto un trabajador especializado en el mismo. Aunque la movilidad por turnos es frecuente y no se detectó la ausencia de movilidad entre turnos en la encuesta, la rotación por turnos entre departamentos de la misma empresa o entre establecimientos de la misma compañía es muy frecuente (65.7\% en el primer caso y $80 \%$ en el segundo). Es notable el trabajo en días de descanso obligatorio en forma muy frecuente $(70.4 \%)$ y lo bajo del nivel esporádico en este indicador (5.6\%), aunque las horas extras son comunes, entre muy frecuentes y regulares, ocupando bajos porcentajes las esporádicas $(14.4 \%)$.

Sin embargo, la movilidad interna no obedece principalmente a las concepciones toyotistas que implican eliminar la monotonía (1.0\%), el pago por conocimientos $(4.9 \%)$ o el estímulo de la polivalencia $(7.8 \%)$, sino por razones vinculadas con el ausentismo, las renuncias o el aumento en la demanda del producto. 


\section{Cuadro 15}

Cuando hay formas grupales de los trabajadores como equipos de trabajo, círculos de calidad, células de producción, cómo participan los trabajadores de la maquila

\begin{tabular}{|lc|}
\hline & Porcentaje \\
\hline Si hay formas grupales & 56.3 \\
\hline No participan en la definición de los presupuesto de producción & 80.7 \\
\hline Discuten y proponen el ajuste de variables del proceso o de maquinaria & 56.1 \\
\hline No participan en los cambios en las especificaciones del producto & 54.4 \\
\hline No participan en el control estadístico del proceso & 57.9 \\
\hline No participan en el control no estadístico del proceso & 52.6 \\
\hline No participan en la relación cliente proveedor & 75.4 \\
\hline Discuten y propone en la identificación de causas de riesgos de trabajo & 65.5 \\
\hline Discuten y proponen en los programas de prevención de riesgos de trabajo & 63.2 \\
No participan en el control de ausencias, permisos y horas extras & 49.1 \\
\hline Discuten y propone en la prevención de conflictos laborales & 52.6 \\
\hline Discuten y proponen la definición de necesidades de capacitación & 52.6 \\
No participan en la elaboración de programas de capacitación & 59.5 \\
\hline No participan en los programas de movilidad interna de los trabajadores & 68.4 \\
\hline
\end{tabular}

Fuente: Elaboración propia a partir de la Encuesta EMIM (2004)

Asimismo, cuando hay formas grupales como círculos, equipos o células, en la mayoría de los establecimientos no participan en decisiones referidas a la producción y puestos de trabajo. La no participación de los trabajadores está seguida de los que discuten y proponen; en forma muy rezagada aparecen aquéllos que deciden. Excepciones son la participación con opiniones en cómo disminuir accidentes y riesgos de trabajo y sus causas, en la prevención de conflictos y en la detección de necesidades de capacitación. Es decir, resulta ficticio decir que en la maquila predominan las nuevas formas de organización del trabajo. Formalmente, pero especialmente en contenido, la organización no corresponde a estas formas, inclinándose seguramente hacia el taylorismo fordismo, aunque a diferencia de la manufactura en general están casi ausentes las formas tradicionales o arbitrarias de organización.

De la encuesta ENESTYC, el porcentaje de establecimientos maquiladores con sindicato es alto (53.9\% en 1999 y $56.8 \%$ en el 2001) y la CTM ocupa el lugar principal, seguida de lejos de la CROC y la CROM. Entre más grande es el establecimiento es más probable que tenga sindicato; sin embargo, el porcentaje de establecimientos maquiladores pequeños con sindicato es alto (42.8\% en 1999). Comparando con el sector manufacturero en general, los porcentajes de trabajadores sindicalizados son semejantes, $46 \%$ en la manufactura contra $42.3 \%$ en la 
Modelos de producción en el sector maquilador: tecnología, organización del trabajo y relaciones laborales

maquila en 1999 y $44.6 \%$ en el 2001. Los especialistas en la maquila han establecido dos modelos de relaciones entre sindicatos y empresas en el sector: por un lado el modelo que predomina en Tijuana con contratos cercanos a los de protección, con práctica ausencia de los sindicatos de los lugares de trabajo y amplias prerrogativas para organizar el proceso de trabajo y gestionar la mano de obra por parte de las gerencias; por otro lado, un modelo corporativo tradicional presente en la maquila de Matamoros que mantiene el monopolio de la contratación de la mano de obra casi al $100 \%$ y obtiene algunas prestaciones económicas adicionales a las de la Ley. Sin embargo, ambos modelos dejan a las gerencias la gestión del proceso productivo sin ingerencias por partes de los sindicatos (Carrillo y Ramírez, 1990; De la O y Quintero, 1992). En comparación con el sindicalismo en general en el país, ni siquiera el caso de Matamoros se asemeja al tipo de relaciones que han establecido los grandes sindicatos nacionales con las empresas de tipo corporativo porque estos últimos (petroleros, electricistas de la CFE, textileros, automotrices de la industria terminal) tienen una importante ingerencia defensiva dentro del proceso de trabajo y aunque sus contratos en general han sido flexibilizados el sindicato sigue teniendo presencia en los ascensos, la distribución de tareas, la movilidad interna, la negociación defensiva de la introducción de nuevas tecnologías o formas de organización del trabajo. No es comparable un contrato colectivo de la maquila de Matamoros con los del núcleo central del corporativismo sindical, están más cerca de Tijuana que de la industria automotriz terminal. En cambio, los contratos de la maquila de Matamoros pudieran asemejarse en prestaciones y bilateralidad entre sindicatos y empresas con los de sindicatos corporativos en empresas manufactureras medianas. Es decir, no basta con considerarlos corporativos tradicionales, sino que habría que agregar de bajo perfil de protección y de bilateralidad. En cambio, el otro modelo sindical y de contratación en la maquila se asemeja al de los contratos y sindicatos de protección. En el medio es posible que hayan aparecido sin tener un amplio ni acelerado desarrollo los sindicatos blanquizados corporativos; es decir, la blanquización de sindicatos de centrales del congreso del trabajo con comportamientos semejantes, por un lado, a los blancos de Monterrey y, por otro lado, a los de la CTM. Son sindicatos que realizan tareas de gestión de la mano de obra para la gerencia y a la vez no dejan de participar en el sistema electoral al lado del PRI o encubiertamente del PAN y mantienen la afiliación y los vínculos con centrales sindicales corporativas.

La flexibilidad laboral tan extendida en las maquilas no significa que estos establecimientos no tengan regulados normalmente a favor de las gerencias, aspectos fundamentales de cómo se gestiona la fuerza de trabajo porque una forma de 
regulación frecuente es precisamente el establecer en los contratos colectivos de trabajo que la decisión será tomada por la gerencia (Kopinak, 1999); es decir, las cifras altas de regulación podrían conceptualizarse como de regulación unilateral en cuanto a decisiones en el proceso de trabajo, conservando comúnmente los sindicatos el monopolio de la contratación de personal formalmente porque en la práctica de la contratación con sindicatos de protección las gerencias tienen amplias prerrogativas también en este renglón.

La mayoría de los establecimientos maquiladores no emplean trabajadores eventuales, aunque el porcentaje de éstos se elevó un poco entre 1999 y 2001, y cuando lo hacen la causa principal es por aumento en el volumen de la demanda del producto. El porcentaje de eventuales era de 3.2\% del total de trabajadores en 1999, de la misma manera los trabajadores subcontratados por horas y por honorarios son muy escasos hasta la fecha. Pero estas cifras se repiten para la manufactura en general, una posible explicación es que al ser los contratos en la maquila de protecciones mínimas, en muchos aspectos no rebasan las de Ley, con mayoría de sindicatos de protección y salarios bajos, además por ser hasta hoy un sector de paz laboral aparente, las empresas pudieran no verse precisadas a buscar subcontratistas o a emplear eventuales, como tampoco preferir la desindicalización.

\section{Cuadro 16}

\section{Distribución porcentual por género y categoría ocupacional en la maquila}

\begin{tabular}{|lr|r|r|r|r|r}
\hline Categoría & \multicolumn{2}{c|}{ Total } & \multicolumn{2}{c|}{ Hombres } & \multicolumn{2}{c}{ Mujeres } \\
\cline { 2 - 7 } & 1999 & \multicolumn{1}{c}{2001} & 1999 & 2001 & 1999 & 2001 \\
\hline Total & 100.0 & 100.0 & 50.7 & 49.7 & 49.3 & 50.3 \\
Directivos & 1.4 & 1.3 & 91.0 & 74.2 & 9.0 & 25.8 \\
\hline Empleados & 18.1 & 19.1 & 59.0 & 54.1 & 41.0 & 45.9 \\
\hline Obreros especializados & 19.3 & 21.0 & 57.5 & 53.4 & 42.5 & 46.6 \\
\hline Obreros generales & 61.2 & 58.6 & 49.9 & 46.4 & 50.1 & 53.6 \\
\hline
\end{tabular}

Fuente: ENESTYC (1999, 2001) INEGI

La maquila sobre todo contrata personal obrero no especializado, en 1999 era el $61.2 \%$ del personal total ocupado que bajó un poco en el 2001 (58.6\%). Estos porcentajes de baja calificación son más altos cuando se trata de mujeres que de hombres. Los obreros especializados sólo alcanzaron el porcentaje de $21 \%$ del personal total ocupado en 2001 cuando eran del $19.3 \%$ en el 1999, seguían en importancia los empleados administrativos. Es decir, la maquila en general sigue 
Modelos de producción en el sector maquilador: tecnología,

organización del trabajo y relaciones laborales

siendo un campo del trabajo poco calificado. El nivel educativo más frecuente en la maquila es el de primaria completa y con la crisis ha disminuido el porcentaje de personal sin instrucción o con primaria incompleta y se ha elevado el de bachillerato, técnico medio o profesionista. Por otro lado, la presencia de hombres se elevó en la década pasada, en 1999 ya alcanzaban más del 50\% del personal total ocupado, aunque se redujo un poco en el 2001. En directivos la presencia masculina era apabullante (91\% en 1999), aunque tuvo una reducción considerable en el 2001 al bajar al 74.2\%; es muy elevada en empleados que son los trabajadores de confianza centrados en técnicos, ingenieros, mandos medios y personal de oficinas; superior el porcentaje de hombres en obreros especializados; y ligeramente superior el de mujeres en obreros generales. Comparando con la manufactura, el porcentaje de obreros especializados en ésta es de $33.4 \%$ contra $19.3 \%$ en la maquila. Todavía hay diferencias en cuanto a composición por género con la manufactura, en la que el personal masculino significaba el $71.1 \%$ contra $50.7 \%$ en la maquila en 1999 .

En el personal ocupado en la maquila predominan los trabajadores con sólo primaria completa o menos (51.1\% en 1999 que bajó a 42.6\% en el 2001) seguidos de secundaria completa (31.1\% en 1999 que aumentó a 35.5\% en 2001). Entre los directivos predominan ampliamente los profesionistas, los empleados se reparten entre secundaria completa y bachillerato o carrera técnica; los obreros especializados tienen mayoritariamente primaria y secundaria completas y los obreros generales, que son la gran mayoría del personal ocupado en la maquila, más de la mitad cuando mucho tienen primaria completa y aunque este porcentaje bajó entre 1999 y 2001 todavía más del 50\% se encuentra en esta situación. Se desmiente el mito del nivel educativo alto en la maquila que han difundido estudios parciales de este sector. La crisis en la maquila se ha traducido como ya hemos visto en una preferencia de los establecimientos que no cierran por trabajadores con mayor nivel educativo, sin que las tendencias de los noventa se reviertan todavía en cuanto al predominio de personal ocupado de bajo nivel educativo, en particular entre los obreros. Según la ENESTYC el nivel de secundaria es el nivel educativo que la mayoría de las maquilas buscan para los obreros especializados y el de primaria completa para los obreros generales, es decir que, independientemente de los niveles de educación disponibles en el mercado de trabajo, la política de contratación de las gerencias maquiladoras coincide con los niveles que se encuentran empíricamente en estas empresas, posible indicador de que no se busca mayor calificación por las características de los procesos productivos. 


\section{Cuadro 17}

Distribución porcentual de años de antigüedad y categoría ocupacional

\begin{tabular}{|c|c|c|c|c|c|c|c|c|c|c|}
\hline \multirow[t]{2}{*}{ Categoría } & \multicolumn{2}{|c|}{ Menos de 1 año } & \multicolumn{2}{|c|}{1 a 3años } & \multicolumn{2}{|c|}{3 a 5 años } & \multicolumn{2}{|c|}{5 a 10 años } & \multicolumn{2}{|c|}{ Más de 10 años } \\
\hline & 1999 & 2001 & 1999 & 2001 & 1999 & 2001 & 1999 & 2001 & 1999 & 2001 \\
\hline Total & 33.5 & 28.8 & 33.8 & 35.4 & 17.4 & 18.2 & 11.3 & 12.1 & 3.9 & 5.5 \\
\hline Directivos & 12.0 & 9.9 & 23.3 & 23.5 & 21.6 & 21.4 & 24.1 & 25.6 & 19.1 & 19.6 \\
\hline Empleados & 24.0 & 18.3 & 32.2 & 33.9 & 22.1 & 19.7 & 15.8 & 18.9 & 5.8 & 8.3 \\
\hline $\begin{array}{l}\text { Obreros } \\
\text { especializados }\end{array}$ & 26.0 & 21.9 & 34.9 & 34.5 & 20.1 & 24.7 & 14.7 & 13.3 & 0.4 & 5.6 \\
\hline $\begin{array}{l}\text { Obreros } \\
\text { generales }\end{array}$ & 38.4 & 32.6 & 33.6 & 34.9 & 15.7 & 16.2 & 9.4 & 11.7 & 2.9 & 4.6 \\
\hline
\end{tabular}

Fuente: ENESTYC (1999, 2001) INEGI

A principios de los noventa, en 1991 (Carrillo y Santibáñez, 1993), la tasa mensual de rotación externa en la maquila era del $10 \%$, aunque esta cifra variaba por ciudades y ramas; las de la frontera norte eran las que tenían cifras más altas de rotación (Tijuana $12.7 \%$ y Ciudad Juárez $10.9 \%$ mensuales) y por ramas la del vestido $15.8 \%$ (De la O y Quintero, 1995).

Para 1999, la mayoría del personal total ocupado (67.3\%) no rebasaba un año de antigüedad en el establecimiento, aunque en el 2001 han sido rebasados por los que tienen entre 1 y 3 años de antigüedad; en cambio los directivos se reparten entre aquellos que han durado entre uno y 10 años. Los empleados están concentrados en la antigüiedad de 1 a 5 años. Los obreros especializados entre 0 y 5 años; en cambio los obreros generales tenían menos de 1 año en 1999, pero en el 2001 han sido rebasados por los que han durado entre 1 y 3 años en el trabajo. Sigue siendo cierto que la mayoría de los trabajadores, que son los obreros generales, tiene poca antigüedad en la maquila, menos de 3 años el $67.5 \%$ y $32.6 \%$ con menos de un año en el 2001. Las tasas de rotación externa son una de las explicaciones de la brevedad de la antigüedad de la mayoría de los trabajadores en la maquila; en estas condiciones es difícil pensar que a pesar de que las nuevas formas de organización del trabajo que exigen identidad con la empresa, involucramiento y participación por parte de los trabajadores pudiera darse de manera profunda en la mayoría de esta clase obrera de antigüedad tan breve en una empresa. Sin embargo, la crisis trajo algunos cambios importantes, los trabajadores tienden a rotar menos que antes y los empleadores prefieren conservar personal de mayor antigüedad con respecto de los de menor tiempo en la empresa.

Los salarios reales y las remuneraciones totales en promedio por persona ocupada en la maquila siempre han sido inferiores a la manufactura en general, aunque 
Modelos de producción en el sector maquilador: tecnología,

organización del trabajo y relaciones laborales

superiores al salario mínimo. La relación entre remuneraciones en la maquila en términos de número de salarios mínimos se ha incrementado desde 1994 en forma sostenida, aunque en el 2002 apenas alcanzó 2.53 veces el salario mínimo. En comparación con las remuneraciones en la manufactura se elevaron desde inicios de los noventa, excepto 1998, 1999 y el 2000, representando en 2003 los de la maquila $64.9 \%$ de los de la manufactura, el salario real en la maquila se ha incrementado desde 1996 sin decaer en estos últimos años de crisis, a pesar de que la productividad ha tenido tasas anuales negativas.

\section{Cuadro 18}

\section{Comparaciones salariales de la Maquila}

\begin{tabular}{|l|l|l|}
\hline Año & $\begin{array}{l}\text { Salario } \\
\text { Maquila/Salario } \\
\text { mínimo }\end{array}$ & $\begin{array}{l}\text { Remuneraciones } \\
\text { Maquila/Manufactura } \\
(\%)\end{array}$ \\
\hline 1994 & 1.88 & 56.0 \\
1995 & 1.94 & 61.0 \\
\hline 1996 & 1.94 & 61.0 \\
\hline 1997 & 2.07 & 63.0 \\
\hline 1998 & 2.10 & 62.0 \\
\hline 1999 & 2.18 & 60.0 \\
2000 & 2.26 & 57.0 \\
\hline 2001 & 2.55 & 63.0 \\
\hline 2002 & 2.53 & 64.8 \\
\hline 2003 & & 64.9 \\
\hline
\end{tabular}

Fuente: STyPS (2003) Estadísticas laborales

En octubre de 2002 el salario por hora en la maquila era de 1.1 dólares la hora contra 1.78 en la manufactura. El salario mensual de obreros en la maquila en ese mes sin considerar prestaciones era de $\$ 3,000.00$ al mes.

La mayor parte de las remuneraciones la conforman sueldos y salarios base, $68.5 \%$ en 1999 que han aumentado considerablemente en el 2001 al alcanzar el 80.2\%; las horas extras constituían un $10 \%$ del total de remuneraciones en 1999, han bajado en el 2001 a $4.5 \%$; las prestaciones sociales también han bajado de un $18.4 \%$ en 1999 a $13.8 \%$ en el 2001. Habría que advertir que en otras remuneraciones se encuentran los bonos por asistencia, puntualidad, productividad, etc., entre todos ocupan un porcentaje muy bajo del total de las remuneraciones, de $3.1 \%$ en 1999 han caído a la irrisoria cantidad de $0.5 \%$ del total de remuneraciones en el 2001. Es decir, la crisis en cuanto a remuneraciones y salarios ha sido afrontada 
por las empresas maquiladoras reduciendo la parte variable, en particular los bonos y estímulos y horas extras, adquiriendo más importancia la fija que corresponde a los salarios base.

\section{Cuadro 19}

Distribución porcentual de las remuneraciones pagadas al personal por rubro en la maquila

\begin{tabular}{|l|r|r|} 
Tipo de remuneración & \multicolumn{1}{|c|}{1999} & \multicolumn{1}{|c|}{2001} \\
\hline Sueldos y salarios base & 68.5 & 80.2 \\
\hline Horas extras & 10.0 & 4.5 \\
Prestaciones & 18.4 & 13.8 \\
\hline Otras remuneraciones & 3.1 & 0.5 \\
\hline
\end{tabular}

Fuente: ENESTYC (1999, 2001) INEGI

Nota: se excluyó el rubro de contribuciones a la seguridad social para hacerlo comparable con otras estadísticas de remuneraciones

\section{Cuadro 20}

\section{Indicadores de redes entre empresas y encadenamientos productivos en la maquila}

\begin{tabular}{|l|c|c|}
\hline Tipo de encadenamiento productivo & 1999 & 2001 \\
\hline $\begin{array}{l}\text { Porcentaje de establecimientos que contrataron } \\
\text { maquilas }\end{array}$ & 18.00 & 0.03 \\
\hline $\begin{array}{l}\text { Porcentaje de la producción total que fue } \\
\text { maquilada }\end{array}$ & 10.44 & 14.10 \\
\hline $\begin{array}{l}\text { Porcentaje de establecimientos que } \\
\text { subcontrataron a otros }\end{array}$ & 4.20 & 2.80 \\
\hline $\begin{array}{l}\text { Porcentaje del valor de la producción realizada } \\
\text { por subcontratistas }\end{array}$ & 4.00 & 5.00 \\
$\begin{array}{l}\text { Porcentaje de establecimientos que fueron } \\
\text { subcontratados por otros } \\
\text { Porcentaje de los ingresos por ser subcontratado } \\
\text { con respecto a los ingresos totales }\end{array}$ & 6.99 & 11.56 \\
\hline
\end{tabular}

Fuente: ENESTYC $(1999,2001)$ INEGI 
Modelos de producción en el sector maquilador: tecnología, organización del trabajo y relaciones laborales

\section{Cuadro 21}

Porcentaje de establecimientos maquiladores que no establecen relaciones con otros en México para realizar diversas actividades

\begin{tabular}{|lr|}
\hline Tipo de cooperación & $\begin{array}{l}\text { Porcentaje que } \\
\text { no lo tienen }\end{array}$ \\
\hline Investigación de mercados y ventas & 93.9 \\
\hline Contratación de personal & 82.5 \\
\hline Capacitación & 77.5 \\
\hline Investigación y desarrollo & 91.8 \\
\hline Publicidad & 91.8 \\
\hline Compra de materias primas & 66.7 \\
\hline Adquisición de maquinaria y equipo & 66.3 \\
\hline Utilización compartida de maquinaria y equipo & 82.7 \\
\hline Otra & 95.9 \\
\hline
\end{tabular}

Fuente: Elaboración propia a partir de la encuesta EMIM (2004)

En cuanto a las articulaciones de las maquilas con otras empresas dentro del territorio nacional, el porcentaje de establecimientos que contrataron maquilas dentro de México para realizar una parte de su producción, el porcentaje del valor de la producción maquilado internamente, el porcentaje que contrató subcontratistas, el porcentaje del valor de la producción subcontratada y el porcentaje de ingresos obtenidos por el establecimiento por realizar tareas de subcontratación son muy bajos tanto para 1999 como para el 2001. Asimismo, los datos recabados de la EMIM muestran que la gran mayoría no realizan investigación de mercados y ventas, contratación de personal, capacitación, investigación y desarrollo, publicidad, compra de materias primas, adquisición de maquinaria y equipo, utilización compartida de maquinaria y equipo o cualquier otra en forma conjunta entre establecimientos. De estas actividades la compra compartida de maquinaria, equipo o materias primas son las más elevadas, aunque lejanas al 50\%. Los datos anteriores son consecuentes, en primer término, con la importancia de la importación de materias primas, maquinaria y equipo del extranjero - que es una de las razones de ser maquila por las exenciones de impuestos. Sin embargo, el régimen fiscal no es suficiente para explicar cómo son escasas otras formas de encadenamiento y cooperación de las maquilas con otras empresas situadas dentro del territorio nacional.

Diversos factores pueden influir en esta incapacidad de la maquila para establecer encadenamientos productivos amplios en México: 
1) Las políticas de las matrices que obligan a la importación de insumos entre filiales como estrategia global o multinacional que mira hacia la rentabilidad de la cadena internacional y no hacia un segmento ubicado en un país en particular, mucho menos hacia el desarrollo del tejido industrial de una nación.

2) Las deficiencias nacionales de las empresas para producir justo a tiempo, con calidad y productividad homogéneas y sostenidas en el tiempo, así como de costos competitivos.

3) El propio régimen jurídico de la maquila que proporciona exención de impuesto de importación de insumos y que con esto no propicia la substitución de proveedores con empresas dentro del territorio nacional (Gruber, 2001).

\section{Conclusiones}

Desde el punto de vista de modelos productivos la mayoría de las maquilas son ensambladoras ( $80 \%$ en el nivel nacional, $64 \%$ en el centro sureste) (Corona, 1994; EMIM, 2003); utilizan tecnología intermedia y baja (maquinizada no automatizada), prácticamente no realizan investigación y desarrollo, sino que la tecnología la obtienen de sus matrices; el control de calidad está muy extendido, pero es de nivel intermedio, preventivo y por medio de observación visual combinada con instrumentos. Han introducido cambios organizacionales, aunque en la mayoría en las formas más simples como los equipos de trabajo. Es decir, es probable que lo que predomine sea el taylorismo fordismo mezclado con aspectos parciales, comúnmente los más sencillos del toyotismo. La mayoría de las maquilas tienen sindicato, aunque otros estudios sugieren que muchos pueden ser o comportarse como si fueran de protección; la mayoría de los trabajadores son de planta, característica general de las manufacturas en México. Los encadenamientos productivos son escasos. La mano de obra se ha ido masculinizando, aunque se ha estabilizado con la crisis, compartiendo actualmente entre hombres y mujeres porcentajes casi iguales; sin embargo, el crecimiento de los trabajadores del sexo masculino no ha estado aparejado con la calificación y la mayoría sean hombres o mujeres no son calificados; el nivel de instrucción sigue siendo el de primaria con la crisis; la antigüedad a subir de menos de 1 año, a menos de tres, las jornadas de trabajo siguen altas, y el porcentaje que representan los bonos por productividad en el total de las remuneraciones es muy bajo y tendió a ser menor; los salarios siguen siendo bajos, aunque hayan aumentado en términos reales no son suficientes para la subsistencia de una familia promedio de acuerdo con el costo de una canasta básica. 
Modelos de producción en el sector maquilador: tecnología, organización del trabajo y relaciones laborales

Estamos lejos de tener en la maquila no sólo a la tercera generación de que habla Jorge Carrillo, sino habría dudas de la forma que adquiere la segunda, al menos no se presenta con alta tecnología y seguramente con fuertes elementos tayloristas y fordistas, además de una mano de obra mal pagada, de alta rotación externa y poco calificada. Durante los años de la crisis de la maquila que corresponden a los del actual gobierno se observa una disminución en el total de establecimiento de los grandes, así como del porcentaje de trabajadores empleados en éstos; asimismo, aumentó la antigüedad de dichos establecimientos, el capital extranjero sigue siendo mayoritario, pero disminuyó apreciablemente. Esto es, las empresas maquiladoras que se fueron o quebraron con la crisis fueron preferentemente las grandes, de capital extranjero, subsidiarias de otras y las más jóvenes. Sin embargo, no ha disminuido su carácter exportador hacia los Estados Unidos ni tampoco la proporción de los insumos importados con respecto de los totales, no hubo en la crisis una sustitución de insumos extranjeros por nacionales, coincidente con las cifras bajas que se mantuvieron de indicadores de encadenamientos productivos. En cuanto a la investigación y desarrollo no hubo cambios, son casi inexistentes. En cambio aumentó el porcentaje de maquilas con uso de maquinaria y equipo más moderno, aunque la mayoría del valor en los activos continuó siendo el atrasado. En relaciones laborales no disminuyó el porcentaje de establecimientos con sindicato y el de trabajadores sindicalizados bajó un poco, pero sigue siendo muy alto; las regulaciones del proceso de trabajo aumentaron, aunque no necesariamente los sindicatos ganaron en bilateralidad y los trabajadores de planta siguen predominando, a pesar de que aumentaron los de tiempo y obra determinada. En cuanto a la mano de obra, los obreros generales siguen siendo la mayoría, pero disminuyeron en estos primeros años del siglo; los hombres se mantuvieron casi iguales a las mujeres, aumentó la antigüedad, la jornada se mantuvo alta y los salarios reales se incrementaron, pero en los ingresos de los trabajadores tendió a ser más importante la parte rígida del salario base, disminuyendo los ingresos por horas extras y por estímulos y bonos. Hay que aclarar que no se trató de ningún proceso evolutivo de quiebra de las más ineficientes y permanencia de las eficientes, puesto que fueron las más grandes y transnacionalizadas las que decidieron dejar el territorio nacional; es decir, las que quedaron no fue sólo por eficientes, sino también por tener mayores dificultades para emigrar de giro o de país. Las relaciones laborales y gestión del personal tendieron a ser más regulados y no por presión sindical, sino para garantizar la unilateralidad gerencial y a la vez para conservar a los trabajadores de mayor calificación, antigüedad, nivel educativo. Sin embargo, la mayoría de los trabajadores continuaron siendo de baja calificación. Los salarios tendieron también hacia la rigidez al predominar en los ingresos los salarios base y disminuir las partes variables de estos. 
Es probable que los modelos productivos en la maquila se muevan entre dos principales tipos, uno de corte taylorista-fordista y otro toyotista precario con dosis fuertes de taylorismo fordismo. Como apuntamos, se trata de dos modelos que se interpenetran y que en México no tienen límites muy bien definidos. En todo caso, ambos son intensivos en mano de obra, la tecnología que utilizan en general es maquinizada, pero no automatizada, aplican aspectos parciales de la Calidad Total, mas con segmentación de tareas entre obreros poco calificados, con los calificados y técnicos e ingenieros. Es difícil pensar que entre la mayoría de estos trabajadores, que corresponden a los obreros generales, con una rotación alta, pudiera forjarse identidad con el trabajo, con la empresa o con el sindicato. Además, como una de las principales ventajas de la maquila es su régimen fiscal; es decir, la exención de impuesto de importación de insumos, maquinaria y equipo, además del de valor agregado, y por el lado de la demanda de sus productos que van principalmente a los Estados Unidos el atenerse mayoritariamente a la regla por la que sólo se cobra como impuesto de importación el valor agregado en México; no es extraño que las maquilas no remonten los bajos niveles de integración nacional o que establezcan débiles encadenamientos productivos en México. Las relaciones laborales son aparentemente muy formales y en efecto una proporción muy elevada de maquilas y trabajadores tienen sindicato; las tasas de regulación laboral son muy altas. Sin embargo, en la mayoría de los casos se trata de un corporativismo pasivo en el proceso productivo que deja hacer a la gerencia y que no reclama mayores prestaciones que las de ley. Una excepción que vale la pena verificar es la situación en la ciudad de Matamoros que, sin embargo, está lejos del núcleo central de las relaciones laborales del modelo de la Revolución Mexicana representado por los grandes sindicatos nacionales de industria como los petroleros.

Tanto el taylorismo fordismo como lo que hemos llamado el toyotismo precario, configuraciones dominantes en la maquila, se basan en el bajo salario y en la intensificación del trabajo y, en esta medida, enfrentan como límites productivos a la resistencia física y mental del trabajador para aumentar la productividad incrementando el desgaste de su fuerza de trabajo, pero sobre todo a la resistencia social que en condiciones diferentes a las de la maquila podría tomar la forma de la huelga, el paro loco o el sabotaje; sin embargo, en la maquila ha seguido más bien el camino de la demanda individual del trabajador en las Juntas de Conciliación y Arbitraje al margen de los sindicatos y sobre todo la rotación voluntaria externa. Muchas de las causas de la rotación que han sido analizadas por los especialistas, que la hay más entre los jóvenes, solteros, de mayor nivel educativo, hombres, pudiera ser por hastío, cansancio, malas condiciones de higiene y seguridad, falta 
Modelos de producción en el sector maquilador: tecnología,

organización del trabajo y relaciones laborales

de capacitación o de carrera ocupacional e incluso las que la atribuyen a las malas condiciones de vida, pueden resumirse en los modelos de producción imperantes en la maquila y su incapacidad para fijar a la fuerza de trabajo, basados en la intensidad del trabajo y el bajo salario, con formas de división del trabajo que segmentan las tareas de operación de las de concepción, con insuficiente capacitación y escalafones muy cortos que limitan las carreras ocupacionales en las empresas. El bajo salario no puede sino asociarse con las malas condiciones de vida, que sólo parcialmente dependen de la falta de infraestructura en servicios públicos de la frontera norte. Si son los jóvenes, no casados, hombres y de mayor nivel educativo los que más rotan, no extraña; son los que tienen menos que perder, los que prefieren la trayectoria laboral nómada a las nuevas cadenas del toyotismo precario. Estas condiciones de operación de los modelos de producción maquiladores, con sus límites en la resistencia de los trabajadores, también impone límites al crecimiento de la productividad, y se pudo llegar a conformar desde los noventa una crisis de productividad del sector, que estalló cuando las condiciones del mercado de los Estados Unidos decayeron a inicios de este siglo. Esto porque el círculo toyotista no se logró cerrar; la elevada rotación, con poca identidad, es difícil que se asocie a una auténtica participación e involucramiento de los trabajadores en la lucha por la competitividad y la productividad, más aun cuando los salarios y los montos de los bonos son escasos. Pero los modelos de producción maquiladores en México abarcan más que a las empresas que están formalmente registradas en este régimen arancelario; características como las mencionadas se pueden encontrar en otras empresas, ramas y zonas que formalmente no son maquilas. Es probable que los modelos de producción dominantes en la maquila sean a su vez los dominantes en las manufacturas mexicanas y que sus límites sean semejantes a los mencionados (De la Garza, 2003).

\section{Bibliografía}

Aguilar, I. (1996), "Competitividad, flexibilidad y rotación de personal en la IME de Televisores de Tijuana", Tesis en opción al grado de Maestro en Desarrollo Regional, Colef.

Alonso, J., J. Carrillo y O. Contreras (2002), “Aprendizaje tecnológico en las maquiladoras del norte de México", Frontera Norte, Vol. 14, enero-junio, pp. 43-82. 
Amsden, A. (1997), "Editorial: Bringing production back in-Understanding government's economic role in late industrialization", World Development, Vol. 25, Núm. 4, Abril, pp. 469.

Barajas, R. (coord.) (1989), Mujer y trabajo en la industria maquiladora de exportación, México: Fundación F. Ebert.

Boyer, R. y M. Freyssenet (2001), Modelos de producción, Buenos Aires: Humanitas.

Carrillo, J (coord.) (1993), Condiciones de empleo y capacitación en las maquiladoras de exportación de México, México: STyPS-Colef.

Carrillo, J yA. Hualde (1997), "Maquiladoras de tercera generación: el caso DelphiGM”, Comercio Exterior, Vol. 47, No. 9, septiembre, pp. 747-757.

Carrillo, J y J. Santibáñez (1993), Rotación de personal en las maquiladoras de exportación de Tijuana, Tijuana: STyPS-Colef.

Carrillo, J. (1989), "Calidad con consenso en las maquiladoras ¿Asociación Factible?”, Frontera Norte, Vol. I, No. 2, julio-diciembre, pp. 105-125.

Carrillo, J. y A. Hualde (2002), Veinte años de estudios sobre la industria maquiladora de exportación en México, Tijuana: Colef, Video.

Carrillo, J. y M.A. Ramírez (1990), "Maquiladoras en la frontera norte: opinión sobre los sindicatos", Frontera Norte, No. 4, julio-diciembre, pp. 121-152.

Corona, Alfonso (1994), "Reestructuración regional en México, variables macroeconómicas y TLC", Problemas del Desarrollo, Vol. 25, enero-marzo, pp. 77-92.

Cortés, F. y R.M. Ruvalcaba (1993), "Desocupados precoces ¿otra cara de la maquila?”, Estudios Sociológicos, No. 33, septiembre-diciembre, pp. 695723.

De la Garza, E. (2001), La formación socioeconómica neoliberal, México: Plaza y Valdés. 
Modelos de producción en el sector maquilador: tecnología,

organización del trabajo y relaciones laborales

(2003), Compañías y trabajadores en México al inicio del siglo XXI, México: STyPS.

De la O, M. E. y C. Quintero (1992), "Sindicalismo y contratación colectiva en las maquiladoras fronterizas, los casos de Tijuana, Cd. Juárez y Matamoros", Frontera Norte, Vol. 4, No. 8, julio-diciembre, pp. 7-88.

(1995), “Trayectorias laborales y estabilidad en las maquiladoras de Matamoros y Tijuana", Frontera Norte, Vol. 7, No. 13, enero-junio, pp. 6792.

(Coords.) (2001), Globalización, trabajo y maquilas, México: Plaza y Valdés.

Dussel, E. (2002), "Ser maquila o no ser maquila", Ponencia para el Seminario Retos y Perspectivas de la Maquila Mexicana, U de G, 30-31 de octubre.

Gambrill, M. (1995), "La política salarial de las maquilas", Comercio Exterior, Vol. 45, No. 7, junio, pp. 545-549.

Gambrill, Mónica (1998), Labor Policy in the Maquiladoras: changes under Nafta.

Gereffi, G., D. Spencer y J. Bair (eds.) (2002), Free Trade and Uneven Development, Philadelphia: Temple University Press.

Gonzalez Arroyo, Miguel (1996), The CAFOR Survey of Maquiladora Workers on Occupational Health and Safety in Tijuana and Tecate, México. Berkeley: Maquiladora Health and Safety Support Network.

González, S. et al. (1995), Mujeres, migración y maquila en la frontera norte, México: El Colegio de México-El Colef.

Gruben, C. William. (2001), “Did Nafta really cause Mexico’s high maquiladora growth?” Center for LatinAmerican Economics, Working Paper CLAE 0301, julio. 
La industria maquiladora (1996), [s.a.], México: CEPAL.

Kenney M. (1998) "Learning Factories or Reproduction Factories", Work and Occupations, Vol. 25, No. 3, agosto, pp. 269-304.

Klein W.M., S. Schuh y R. K. Triest (2002), Job creation, job destruction and international competition: a literature review, Working Paper No. 02-7, Federal Reserve Bank of Boston.

Kopinak, K. (1999), Desert Capitalism, Arizona:The University of Arizona Press.

Lara, A. (1998), Aprendizaje tecnológico y mercado de trabajo en las maquiladoras japonesas, México: Miguel A. Porrúa.

Rodríguez,A. (1993), "Las zonas industriales orientadas a la exportación y la ventaja competitiva de los costos", Estudios Sociales, Vol. IV, No. 7, enero-junio, pp. 147-167.

Sánchez, R. (1990), "Condiciones de vida de las trabajadoras de la maquila en Tijuana y Nogales”, Frontera Norte, No. 4, julio-diciembre, pp. 153-181.

Shaiken, H. (1990), México in the Global Economy, La Jolla: Center for USMexican Studies.

Sklair, L. (1992) “The Maquilas in México: a global perspective”, Bulletin of Latin American Research, Vol. 11, No. 1, enero.

Wilson, P. (1996), Las nuevas maquiladoras en México, Guadalajara: U de G.

Wilson, T.D. (2002), "The masculinization of the Mexican maquiladoras", Review of Radical Political Economics, Vol. 34, 1, invierno 2002, pp. 3-17. 